\title{
New Therapeutic Approaches to Osteoradionecrosis: Literature Review
}

\section{Novas Abordagens Terapêuticas para a Osteorradionecrose: uma Revisão de Literatura}

\author{
Juliana Borges de Lima Dantas ${ }^{\mathrm{a}}$; Júlia Vianna Neri Andrade Reis ${ }^{\mathrm{b}}$ \\ ${ }^{a}$ Federal University of Bahia, Stricto Sensu Graduate Program in Interactive Processes of Organs and Systems. BA, Brazil. \\ ${ }^{b}$ Federal University of Bahia, Stricto Sensu Graduate Program in Dentisty and Health \\ E-mail: julianadantas.pos@bahiana.edu.br \\ Recebido em: 16/07/19 \\ Aprovado em: 30/08/19
}

\begin{abstract}
Radiotherapy is an important treatment of oral and maxillofacial malignancies. Among the various effects of this locoregional therapy, osteoradionecrosis (ORN) plays a prominent role due to its physical and psychological impact on cancer patients. In the literature, the therapeutic approach of ORN varies from a conservative to invasive surgery treatment. Objective: collect in the scientific literature, concise and current information about the benefits of using these therapies in the ORN. The present literature review selected articles based on the titles that addressed osteoradionecrosis treatment, as well as the evaluation systems adopted. After previous analysis, 22 relevant articles were included on the proposed theme. According to the literature, several hypotheses have been established to explain the etiopathogenesis of ORN, as numerous evaluation systems have been developed in the last years. Regarding the main therapeutic modalities used, new less invasive therapies have acquired space, such as ozone therapy, laser therapy associated with photodynamic therapy and drugs, such as vitamin, antifibrotic and anti-resorptive. However, in spite of the promising results, new randomized clinical trials have to be performed in an attempt to discover the real effectiveness of these therapies in the ORN. Therefore, it becomes a challenging issue for dental surgeons, since it requires the constant monitoring and long term of these patients, due to the risk of progression or recurrence of this condition.
\end{abstract}

Keywords: Radiotherapy. Osteoradionecrosis. Conservative Treatment. Ozone. Photochemotherapy.

\section{Resumo}

A radioterapia compreende um tratamento importante no tratamento de tumores malignos orais e maxilofaciais. Dentre os diversos efeitos oriundos desta terapia locoregional, a osteorradionecrose (ORN) apresenta um papel de destaque devido ao seu impacto fisico e psicológico ao paciente oncológico. A abordagem terapêutica da ORN pode variar do tratamento conservador ao tratamento invasivo através da cirurgia. Objetivo coletar na literatura científica informações concisas e atuais acerca dos beneficos do uso dessas terapias na ORN. A presente revisão narrativa de literatura teve a seleção de artigos com base nos titulos que abordaram as terapias empregadas na osteorradionecrose, bem como os sistemas de avaliação adotados. Após análise prévia, foram incluidos 39 artigos relevantes sobre a temática proposta. De acordo com a literatura, várias hipóteses foram estabelecidas para explicar a etiopatogenia da ORN, assim como inúmeros sistemas de avaliação foram desenvolvidos nos últimos anos. Com relação as principais modalidades terapêuticas empregadas, novas terapias menos invasivas têm adquirido espaço, a exemplo da ozonioterapia, laserterapia associada à terapia fotodinâmica e medicamentos antioxidantes, antifibróticos e antireabsortivos. Todavia, apesar dos resultados promissores, novos ensaios clínicos precisam ser realizados, para se descobrir a real eficácia dessas terapias na ORN. Portanto, torna-se uma questão desafiadora para os Cirurgiões-dentistas, uma vez que requer o monitoramento constante e a longo prazo desses pacientes, devido ao risco de progressão ou recidiva desta afecção.

Palavras-chave: Radioterapia. Osteoradionecrosis. Tratamento Conservador. Ozônio. Fotoquimioterapia.

\section{Introduction}

Radiotherapy comprises an important therapeutic modality in the treatment of oral and maxillofacial malignancies. Despite promoting the destruction and/or local control of the tumor with significant improvement in survival of these patients, late adverse effects may occur, because this therapeutic modality is not selective, i.e., it causes damage to malignant and healthy tissues. Among the various effects from radiotherapy, the locoregional osteoradionecrosis (ORN) presents a prominent role, because it cannot always be avoided, besides causing psychological and physical impact to the patient in question ${ }^{1}$.

ORN of jaws represents one of the most disturbing late effects and affects approximately $20 \%$ of patients subjected to radiotherapy in the head and neck region ${ }^{2}$. The rate of incidence of this condition is greater in the jaw in relation to the maxilla due to increased bone density and reduced vascularization, with a percentage that can vary from $2.6 \%$ to $22 \%{ }^{3.4}$. This condition presents numerous settings that complement one another. According to Wong et al. ${ }^{5}$ ORN can be defined as an ischemic necrosis of the bone associated with soft tissue necrosis induced by radiation, with variable extension and slow healing, which occurs in the absence of tumor necrosis, recurrence of cancer or local metastatic disease. Additionally, it can be also defined as an area of exposed bone that persists for three months or more, when all other possible diagnosis were excluded ${ }^{4.6}$. Since there is evidence that the ORN can 
be detected radiographically without any exposure of the oral mucosa or skin cervicofacial, Støre and Boysen ${ }^{7}$, added this new observation in its classification. Despite the lack of a standardized and unified definition, this disease can be broadly characterized by different extensions of bone necrosis combined with defects in soft tissues. These varying degrees of bone destruction make it essential for the creation of a system of staging, in an attempt to help provide an adequate therapeutic strategy ${ }^{1}$.

ORN can occur spontaneously, however, generally is associated to a traumatic event. It can manifest soon after the radiotherapy treatment or even years after completion of radiation therapy ${ }^{8}$. Its clinical aspect can be varied, in which some cases are totally asymptomatic until those that cause severe pain, purulent drainage with possible formation of fistula, deconfiguration and mandibular functional impairment, which directly affects the quality of life of these patients 9 .

The therapeutic approach of ORN presents a common sense in the literature. Its management varies from a conservative treatment, which includes the use of various medicines, hyperbaric oxygen, laser therapy associated with photodynamic therapy and ozone therapy, the invasive treatment through surgery with radical resection and reconstruction with a free flap. The prevention of this condition should be a priority in the dental team through the elimination of possible infectious foci before starting the locoregional radiotherapy. In cases of necessity of traumatic dental procedures after radiotherapy, procedures must be used that aim to minimize this risk ${ }^{10}$.

Based on context that new conservative therapies have gained space in the management of the ORN and due to the importance of studying the healing potential of these new approaches, the present literature review aims to collect, in scientific literature, concise and current information about the benefits of the use of these therapies in the recovery process from this condition.

\section{Development}

\subsection{Methodology}

The strategy for defined methodology for this study was a narrative review of the literature based on research of articles held in the Pubmed database in the period from June 2018 to July 2018, using the intersection of the following descriptors Decs/Mesh in English "Osteoradionecrosis" and "treatment", "osteoradionecrosis" and "conservative treatment".

The selection of the articles was based on the titles that addressed the current therapies in the management of osteoradionecrosis, as well as its pathophysiology and the most used evaluation systems.

After analysis, 39 articles between the period of 1983 to 2018 were included, because the relevance of the proposed theme.

\subsection{Pathophysiology of ORN}

Various hypotheses were established to explain the etiology and pathogenesis of ORN. The theory introduced by Marx ${ }^{11}$, which includes the " $3 \mathrm{H}$ " - hypoxia, Hypocellularity and hypo vascularity as causal factors, is currently the most publicized one.

However, advances in pathophysiology of ORN have shown that radiotherapy promotes increased fibrosis, in virtue of the deregulation of the fibroblastic activity, with tissue atrophy, which promotes damage to the micro vessels and increases the local inflammatory activity, through the production of TNF- $\alpha$, fibroblast growth factor (FGF) and reactive oxygen species (ROS). This inflammatory activity can persist for many years after radiotherapy ${ }^{8}$.

According to Delanian et al. ${ }^{12}$, ORN offers 3 distinct phases. The first represents a pre-fibrotic phase, which occurs in the first months after radiotherapy and is usually asymptomatic. There is a predominance of alterations in endothelial cells with nonspecific chronic inflammatory response, which results in an increase in vascular permeability, with consequent formation of edema, thrombosis and exposure of the connective tissue. During this phase, the fibroblasts are activated, differentiating into myofibroblasts. The second phase is an organized stage which is constituted by the predominant presence of abnormal fibroblastic activity and there is disruption of the extracellular matrix. During the third phase or fibro-late atrophic phase, the attempt of tissue remodeling results in the formation of unhealed damage fragile fabrics which entail at high risk of late inflammation reactivated in case of injury or local trauma, in which bone can result in necrosis. This last phase can last from 5 to 30 years after the radiotherapy.

\subsection{Systems of evaluation of ORN}

The effects of the ORN vary greatly, and thus it is necessary to determine an effective classification, which will guide not only the diagnosis but also the treatment plan. Several classifications have been developed in the last 30 years to assist this process, however, few of them cover this condition completely ${ }^{9}$. Currently, there are some systems in use which are based on the physiopathology of this condition. In 1983, Marx ${ }^{11}$ described the origin of the ORN through the triad composed by hypoxia, hypocellularity and hypo vascularity. Based on this finding, Marx himself ${ }^{11}$ developed a classification toward the patient response to hyperbaric oxygenation (HBO). This classification has advantages, but involves the use of HBO, which until the time of the definition of the classification system in question, was the only treatment with proven efficacy. However, this classification is not applicable in patients who are not treated with $\mathrm{HBO}$, which makes its use restricted. Later, Epstein et al. ${ }^{4}$, developed a classification in accordance with the progression of ORN. This system was completely innovative, because it provided a form of guidance that determines the appropriate time of treating this disease (Table 1). 
Table 1 - Staging of ORN according to Epstein et al., $1987^{4}$.

\begin{tabular}{|c|l|}
\hline Staging & \\
\hline I & Resolved \\
\hline Ia & Absence of pathological fracture \\
\hline Ib & Pathological Fracture \\
\hline II & Chronic, absence of progression of ORN \\
\hline IIa & Absence of pathological fracture \\
\hline IIb & Pathological Fracture \\
\hline III & Active, progression of ORN \\
\hline IIIa & Absence of pathological fracture \\
\hline IIIb & Pathological Fracture \\
\hline
\end{tabular}

Source: Research data.

In an attempt to obtain a complete system that involves the issues related to the signs, symptoms and treatment of ORN, Pavy et al. ${ }^{13}$ developed a scale that records the degree of morbidity of the patient (Table 2).

Table 2 - Analytical scoring system of objective subjective management (SUM) of ORN

\begin{tabular}{|c|l|}
\hline Score & \\
\hline 1 & Minimum symptoms. No treatment. \\
\hline 2 & Moderate symptoms. Conservative treatment \\
\hline 3 & $\begin{array}{l}\text { Severe symptoms that affect the daily life. Invasive } \\
\text { treatment. }\end{array}$ \\
\hline 4 & Functional irreversible damage. Extensive intervention. \\
\hline
\end{tabular}

Source: Research data.

In a third classification, Notani et al. ${ }^{14}$ systematized ORN according to its anatomic extension. This classification was postulated by means of a series of cases obtained by this study group. However, this classification does not mention the associated symptoms, which are crucial in the management of this condition (Table 3 ).

Table 3 - Staging of ORN

\begin{tabular}{|c|l|}
\hline Staging & \multicolumn{1}{|c|}{ Description } \\
\hline I & ORN confined to alveolar bone. \\
\hline II & $\begin{array}{l}\text { ORN limited to the alveolar and/or mandibular bone } \\
\text { above level of the inferior alveolar canal }\end{array}$ \\
\hline III & $\begin{array}{l}\text { ORN involving the jaw below the level of alveolar canal } \\
\text { and/or cutaneous fistula and/or pathological fracture }\end{array}$ \\
\hline
\end{tabular}

Source: Research data.

More recently, some classifications were imposed on an attempt to obtain an ideal system. Lyons et al. ${ }^{9}$, developed a classification that is based on the extension of the condition and its management through the use of pentoxifylline, an antifibrotic drug (Table 4).

Table 4 - Classification of ORN

\begin{tabular}{|c|l|}
\hline Stage & \multicolumn{1}{|c|}{ Description } \\
\hline 1 & $\begin{array}{l}<2.5 \mathrm{~cm} \text { in length of the bone affected (damaged or } \\
\text { exposed); asymptomatic; only treatment with medicine. }\end{array}$ \\
\hline 2 & $\begin{array}{l}>2.5 \mathrm{~cm} \text { in length of bone; asymptomatic, includes } \\
\text { pathological fracture and/or nerve involvement; drug } \\
\text { treatment only, unless there is dental sepsis or loose } \\
\text { bone/necrotic tissue. }\end{array}$ \\
\hline 3 & $\begin{array}{l}>2.5 \mathrm{~cm} \text { in length of bone; symptomatic, but without } \\
\text { another characteristic despite the medicamentous } \\
\text { treatment; consider the debridement of loose or } \\
\text { necrotic bone, and local pedicled flap. }\end{array}$ \\
\hline 4 & $\begin{array}{l}>2.5 \mathrm{~cm} \text { in length of bone; pathologic fracture, } \\
\text { involvement of the inferior alveolar nerve and/or oral } \\
\text { fistula/skin. Reconstruction with free flap if the patient } \\
\text { presents good general health. }\end{array}$ \\
\hline
\end{tabular}

Source: Research data.
However, the clinical characteristics relevant to the original disease were not included in this system, in addition to losing their efficiency of classification when the anti-fibrotic tissue factor is removed. Whereas in the staging elaborated by Karazoglu et al. ${ }^{10}$, the approach was more extensive and is based on a combination of clinical and radiological findings, symptoms, and presence or absence of oral and/or cutaneous fistulas in patients with ORN located in the mandibular region (Table 5).

Table 5 - Classification of ORN of the jaw

Stage 0: The mandibular bone exposure of less than one month; no evidence of changes in plain radiographs (panoramic or periapical radiography ).

Stage I: Exposure of mandibular bone for less than one month; no evidence of changes in plain radiographs (panoramic or periapical radiography ). Asymptomatic or with cutaneous fistula (IA), or symptomatic or with the presence of cutaneous fistula (IB).

Stage II: Exposure of the mandibular bone for at least one month; alterations present in plain radiographs (panoramic or periapical radiography), but without the involvement of the lower edge of the jaw. Asymptomatic or with cutaneous fistula (IIA), or symptomatic or with the presence of cutaneous fistula (IIB).

Stage III: Exposure of the mandibular bone for at least one month; alterations present in plain radiographs (panoramic or periapical radiography), with involvement of the lower edge of the jaw, regardless of any signals and symptoms.

Source: Research data.

The most recent classification proposed by $\mathrm{Hu}$ et al. ${ }^{1}$ was performed using radiographic evidence of bone necrosis in the irradiated region associated with symptoms presented by the patients. This system is similar to the classification proposed earlier by Karazoglu et al. ${ }^{10}$.

\subsection{Treatments of ORN}

The treatment of ORN in mandibular region correlates with the severity of the disease, and basically consists of surgical resection and the use of conservative therapy, which may be associated or not. The latter consists in the use of topical and systemic antibiotics, application of $\mathrm{OHB}$ and maintaining a satisfactory oral hygiene. Recently, new less invasive therapies have gained space, as the ozone therapy , laser therapy and certain classes of drugs. Compared to the mandibular ORN, the maxillary condition shows a less aggressive clinical course in virtue of a lower bone volume associated with an increased blood flow, and more favorable anatomical characteristics . For that reason, the conservative treatment and the sequestrectomy may be sufficient, even in cases of advanced lesions ${ }^{1}$. Thus, the therapeutic modalities mentioned below will be geared mainly to the management of ORN in the mandible, given their greater predisposition.

\subsubsection{Antibiotic therapy associated with oral hygiene}

The first conservative approaches in ORN, which include the instruction of rigorous oral hygiene associated with an 
effective antibiotic coverage, have restricted indications in patients with the disease at an early asymptomatic or mildly symptomatic stage. According to the literature, the exclusive use of these conservative measures presents complete resolution of clinical symptoms in only $15 \%$ of $\operatorname{cases}^{15}$. The risk of progression of this disease with this type of conduct has stimulated the discovery of new therapies by some researchers, in an attempt to reduce the indication of surgical intervention to remove necrotic bone.

\subsubsection{Hyperbaric oxygenation (OHB)}

Therapy with hyperbaric oxygen (OHB) has been used since the decade of 60 for the treatment of severe complications induced by radiotherapy in the head and neck region, including ORN. The mechanisms of OHB action is based on the increase in oxygen supply to tissues, hypoxic stimulation of fibroblast proliferation, collagen formation and angiogenesis, which favor the tissue repair. In addition, it can have bactericidal and bacteriostatic effects ${ }^{16}$. However, treatment with $\mathrm{OHB}$ presents conflicting results, perhaps by the presence of heterogeneous study designs ${ }^{17.18}$. These methodological differences were identified in the systematic review performed by Peterson et al. ${ }^{19}$ It was observed a very wide variation in rates (19\% to $93 \%$ ) of resolution of ORN with the use of HBO. In the updated review of Cochrane ${ }^{20}$ about OHB in ORN, it can be concluded that its routine application can be justified in some specific selected cases .

In the retrospective study conducted by Nolen et al. ${ }^{21}$, a comparison was performed among the results after surgical mandibular reconstruction associated with free flap in patients with a history of local radiotherapy and which were previously subjected to therapy with $\mathrm{HBO}$ in relation to the group that was subjected to the same surgical procedure, however there was no preventive therapy associated with it. The results showed that there was no significant difference between the two groups, demonstrating the non-confirmation of the hypothesis that the experimental group (HBO) would have fewer complications, and in fact their effectiveness would have proven in the prevention of ORN. Therefore, the authors suggest that the beneficial impact of $\mathrm{HBO}$ on the tissues in the post- surgical procedure has a relationship between the proper range of preventive therapy with surgical intervention.

Although $\mathrm{OHB}$ is a proven therapy as part of a strategic system in selected cases of $\mathrm{ORN}^{20}$, it is important to identify which patients will not respond to this therapy, and thus the additional cost and increase in the treatment time would be avoided $^{21}$.

\subsubsection{Pentoxifylline, Tocopherol and Clodronate}

Pentoxifylline is derived from methylxanthine, which has been used in an isolated manner to treat complications related to fibrosis after radiotherapy in head and neck for more than 20 years. It also provides an indication for the treatment of vascular disorders, for example the ischemic heart disease.
Its action occurs through the promotion of vasodilation, in addition to the anti-inflammatory action directly on the TNF- $\alpha$ and increased activity of erythrocytes ${ }^{22}$. Since then, it has been increasingly used, mainly in association with the tocopherol and, in more severe cases, in triple combination with the clodronate. Until the present moment, randomized controlled prospective studies on this conservative therapy were not published, however, some studies of case series have shown promising results with the use of pentoxifylline associated with tocopherol, which ends up challenging the theory traditionally proposed of hypo vascularity, hypoxia and hypocellularity through replacement by new fibro trophic theory as the mechanism of action of $\mathrm{ORN}^{23}$.

Tocopherol (vitamin E) is an antioxidant agent that modulates the expression of various genes, with direct action on the RSOs, anti-fibrotic action with a decrease in the expression of genes associated with the production of matrix metalloproteinases (MMP-1) 1 and beta fibroblastic growth (TGF- $\beta$ ). The synergistic use of these two therapeutic modalities potentiate the antioxidant actions and helps in the control of $\mathrm{ORN}^{24}$. The combined treatment consists of the use of pentoxifylline of $400 \mathrm{mg} 2 \mathrm{x}$ a day and tocopherol of 1,000 IU, $1 \mathrm{x}$ a day ${ }^{25}$.

Pentoxifylline and vitamin $\mathrm{E}$ are indicated for the treatment of small areas of ORN in virtue of the high rates of success through clinical and symptomatic resolution of such condition. Larger areas of necrosis can be stabilized and resolved with the addition of clodronate, but it is possible that there is no resolution only with the triple therapeutic conservative combination $^{8,23,26}$. Unlike the hyperbaric oxygenation, which requires a considerable amount of equipment, besides being a time-consuming, claustrophobic and expensive technique, these agents are cheaper, easy to obtain and have few side effects $^{24}$. It is worth mentioning that the time of use of these drugs is directly proportional to the severity of $\mathrm{ORN}^{26}$.

Clodronate is a first-generation bisphosphonate with countless actions. As all the bisphosphonates, it inhibits the osteoclastic activity with consequent reduction of bone resorption. It also decreases the recruitment of osteoclasts from bone marrow and shortens the half-life of these cells ${ }^{27}$. In the literature it is well established that the use of bisphosphonates may be associated with a negative phenomenon, which is the osteonecrosis related to medicines. However, its beneficial effect in the reduction of neurological symptoms associated to plexopathies induced by radiotherapy, makes its indication be performed with a frequency in cases of refractory or advanced ORN, especially in association with pentoxifylline and vitamin E, known as the protocol Pentoclo ${ }^{28}$. Pentoclo was tested by means of a prospective cohort study conducted by Delanian et al. ${ }^{26}$, in 54 patients subjected to radiotherapy in the head and neck region, and with the refractory ORN after initial treatment with surgery and HBO. It was observed that the long-term treatment was effective, because all patients had a complete recovery in an average of 9 months. In addition, 
Pentoclo was well tolerated by the patients. It is worth mentioning that, in $67 \%$ of the cases, there was an association of surgery with this therapeutic approach. According to the authors, this decision was taken in certain cases in order to accelerate the healing process. Thus, despite the promising results of Pentoclo in the treatment of this advanced condition, new randomized clinical trials need to be performed, in an attempt to discover the real effectiveness of this protocol in the ORN, in addition to evaluating its effect in the long term and its possible effects.

\subsubsection{Low-power laser (BPL) associated with Photodynamic Therapy (PDT)}

The use of low-power laser (BPL) associated with photodynamic therapy (PDT) for the treatment of ORN remains under notified. LPB has analgesic, anti-inflammatory and photo biomodulator action ${ }^{29}$. PDT consists of the use of a chemical substance with photosensitizing properties in biological tissues, which is activated by exposure to light, with specific wavelength $(660 \mathrm{~nm})$, in the presence of oxygen, with the goal of promoting disinfection in contaminated regions $^{30}$. Another beneficial effect of this therapy extends to surrounding soft tissues, as well as the stimulation of the synthesis of collagen and gingival fibroblasts ${ }^{31}$. The union of these two therapies will promote a significant reduction of the microbial load associated with the acceleration of tissue repair and decrease of painful symptoms. In addition, they are atraumatic techniques and with minimum adverse effect ${ }^{29}$.

In a recent prospective experimental study, the concomitant clinical effect of LBP and the PDT was evaluated in lesions of ORN in different stages, in patients previously subjected to locoregional radiation therapy. The results showed a clinical improvement of $100 \%$ of the patients subjected to this joint therapy through the control of the infected lesions, remission of ORN and partial or total repair of the oral mucosa. Therefore, the authors stated that the LBP/PDT were fundamental for the control of necrosis associated with radiotherapy, reinforcing the importance of its applicability and indication ${ }^{32}$.

\subsubsection{Ozone therapy}

Ozone is a molecule that has three atoms of oxygen $\left(\mathrm{O}_{3}\right)$ energetically unstable, which depends on the conditions of temperature and pressure. It can be transported in water, unsaturated vegetable oil and gas form ${ }^{33}$. In dentistry, there is a growing increase in its use, because of the numerous beneficial properties already proven, for example the antimicrobial, analgesic, anti-inflammatory, immunomodulary and stimulating activity of the circulatory system, with increased rates of hemoglobin, blood cells and tissue oxygenation ${ }^{34}$.

Until the present moment, there is no internationally accepted protocol for the management of bone necrosis through the ozone therapy due to lack of studies proving its effectiveness. However, preliminary studies have been showing promising results of this therapy in the management of ORN and osteonecrosis associated to medicines ${ }^{35.36}$, and without contraindication for concomitant use with surgery or even with the antibiotic therapy ${ }^{36}$.

In case report conducted by Batinjan et al. ${ }^{35}$, the preventive effect of ozone on tissue healing after multiple extractions for patients with a high risk of development of t ORN showed positive results, with acceleration of tissue repair. The authors themselves stated that future studies with larger number of clinical cases or even the realization of randomized clinical trials with ozone therapy should be performed in an attempt to obtain a preventive and ideal therapeutic protocol and with minimal effect in patients who are candidates for the development of ORN. More studies that relate the ozone with a necrosis associated with the use of medications can be observed in the literature. Some have used $\mathrm{O}_{3}$ through the vehicle gas in the treatment of patients with avascular necrosis in the jaw and can be seen its positive influence on the metabolism of site oxygen, in addition to its antibacterial properties. In addition, it was not verified the presence of tissue injury, quite the contrary, the bone structure restauration was observed $^{36.37}$.

Although there are few studies that relate the ozone with ORN, some works published previously associated his therapeutic agent with osteonecrosis associated with the use of medications, which may assist in directing new future research, even though the pathophysiology of these disorders is different.

\subsubsection{Surgery}

Although several methods of treatment of ORN have been suggested, in general, there are two main categories: conservative or surgical treatment. In cases of ORN presenting fractures and extra-oral fistula, the treatment requires surgical resection, in association with the reconstruction and transfer of free tissue ${ }^{16}$. In a study carried out by Dai et al. ${ }^{38}$, it has been demonstrated that surgical intervention (debridement and block resection), was effective in the treatment of refractory ORN after initial conservative treatment, which included the systemic antibiotic therapy associated with topical antimicrobial use and rigorous oral hygiene in patients with advanced ORN. Based on this result, the authors understand that although the priority should be given to conservative treatment, when this is not responsive, the surgical treatment should be performed. They also consider that the therapeutic regimes need to be more individualized and based on the severity of ORN.

However, despite being well established in the literature, that in cases of advanced ORN this type of approach should be performed, high rates of recurrence $(25 \%)$ are related to the implementation of this procedure ${ }^{39}$. This high incidence may be justified, because the surgical debridement of necrotic inflamed areas and with fragile irradiated tissue, associated 
with the inability of proper covering of the bone exposed by the soft tissue, can aggravate the condition and convert stable ORN for a more devastating process ${ }^{9}$. Thus, it is necessary to search for new conservative therapies for use alone or as an adjuvant in the management of ORN, since the surgical approach will not always prevent the recurrence of this condition, in addition to promoting, in many cases, the mutilation of such patients.

\section{Conclusion}

ORN is a heterogeneous condition and increasingly common in oncologic patients who underwent radiotherapy in the head and neck region. The most effective treatment for this condition is still controversial and should be individualized, because there is a guideline widely accepted in the literature, in addition to the treatments require a long period of intervention. Therefore, it becomes a challenging issue for dental surgeons, since it requires the constant monitoring and due to the risk of progression or recurrence of this condition. In addition, the mechanism of action of conservative therapies has not been fully elucidated, with the need for further controlled studies, in an attempt to obtain more conclusive results, thus improving the quality of life of those patients.

\section{References}

1. He Y, Liu Z, Tian Z, Dai T, Qiu W, Zhang Z. Retrospective analysis of osteoradionecrosis of the mandible: proposing a novel clinical classification and staging system. Int J Oral Maxillofac Surg 2015;44(12):1547-57. doi: 10.1016/j. ijom.2015.04.006.

2. McLeod NM, Bater MC, Brennan PA. Management of patients at risk of osteoradionecrosis: results of survey of dentists and oral \& maxillofacial surgery units in the United Kingdom, and suggestions for best practice. Br J Oral Maxillofac Surg 2010;48:301-4.

3. Thorn JJ, Hansen HS, Specht L, Bastholt L. Osteoradionecrosis of the jaws: clinical characteristics and relation to the field of irradiation. J Oral Maxillofac Surg 2000;58:1088-95.

4. Epstein JB, Wong FL, Stevenson-Moore P. Osteoradionecrosis: clinical experience and a proposal for classification. J Oral Maxillofac Surg 1987;45:104-10.

5. Wong JK, Wood RE, McLean M. Conservative management of osteoradionecrosis. Oral Surg Oral Med Oral Pathol Oral Radiol Endod 1997;84:16-21.

6. Harris M. The conservative management of osteoradionecrosis of the mandible with ultrasound therapy. Br J Oral Maxillofac Surg 1992;30:313-8.

7. Støre G, Boysen M. Mandibular osteoradionecrosis: clinical behaviour and diagnostic aspects. Clin Otolaryngol Allied Sci 2000;25:378-84

8. McLeod NMH, Pratt CA, Mellor TK, Brennan PA. Pentoxifylline and tochoperol in the manegement of patients with osteoradionecrosis, the Porstmouth experience. Br J Oral Maxillofac Surg 2012;50:41-4.

9. Lyons A, Osher J, Warner E, Kumar R, Brennan P.
Osteoradionecrosis: a review of current concepts in defining the extent of the disease and a new classification proposal. Br J Oral Maxillofac Surg 2014;52:392-5. doi: 10.1016/j. bjoms.2014.02.017

10. Karagozoglu KH, Dekker HA, Rietveld D, Bree R, Schulten EAJM, Kantola S. Proposal for a new staging system for osteoradionecrosis of the mandible. Med Oral Patol Oral Cir Bucal 2014;1(19):433-7. doi: 10.4317/medoral.19623

11. Marx RE. Osteoradionecrosis: a new concept of its pathophysiology. J Oral Maxillofac Surg 1983;41:283-8.

12. Delanian S, Martin M, Housset M. Iatrogenic fibrosis in cancerology (1): descriptive and physiopathological aspects. Bull Cancer 1993;80:192-201.

13. Pavy JJ, Denekamp J, Letschert J, Littbrand B, Mornex F, Bernier J, et al. EORTC late effects working group. Late effects toxicity scoring: the SOMA scale. Radiother Oncol 1995;31:1043-7.

14. Notani K, Yamazaki Y, Kitada H, Sakakibara N, Fukuda H, Omori K, et al. Management of mandibular osteoradionecrosis corresponding to the severity of osteoradionecrosis and the method of radiotherapy. Head Neck 2003;25:181-6.9.

15. Epstein J, van der Meij E, McKenzie M, Wong F, Lepawsky M, Stevenson-Moore P. Postradiation osteonecrosis of the mandible: a long-term follow-up study. Oral Surg Oral Med Oral Pathol Oral Radiol Endod 1997;83(6):657-62.

16. Teng MS, Futran ND. Osteoradionecrosis of the mandible. Curr Opin Otolaryngol Head Neck Surg 2005;13:217-21.

17. Shaw RJ, Danda J. Hyperbaric oxygen in the management of late radiation injury to the head and neck. Part 1: treatment. Br J Oral Maxillofac Surg 2011;49(1):2-8.

18. Shaw RJ, Butterworth C. Hyperbaric oxygen in the management of late radiation injury to the head and neck. Part 2: prevention. Br J Oral Maxillofac Surg 2011;49(1):9-13.

19. Peterson DE, Doerr W, Hovan A, Pinto A, Saunders D, Elting LS. Osteoradionecrosis in cancer patients: the evidence base for treatment-dependent frequency, current management strategies, and future studies. Support Care Cancer 2010;18:1089-98.

20. Bennett MH, Feldmeier J, Hampson NB, Smee R, Milross C. Hyperbaric oxygen therapy for late radiation tissue injury. Cochrane Database Syst Rev 2016;28;4:CD005005. doi: 10.1002/14651858.CD005005.pub4.

21. Nolen D, Cannady SB, Wax MK, Scharpf J, Puscas L, Esclamado RM, et al. Comparision of complications in free flap reconstruction for osteoradionecrosis in patients with or without hyperbaric oxygen therapy. Head Neck 2014;36:1701-04.

22. Horvath B, Marton Z, Halmosi R, Alexy T, Szapary L, Vekasi $\mathrm{J}$, et al. In vitro antioxidant properties of pentoxifylline, piracetam, and vinpocetine. Clin Neuropharmacol 2002;25:37-42.

23. Delanian S, Depondt J, Lefaix JL. Major healing of refractory mandible osteoradionecrosis after treatment combining pentoxifylline and toco-pherol: a phase II trial. Head Neck 2005;27:114-23.

24. Lyons AJ, Brennan PA. Pentoxifylline: a review of its 
use in osteoradionecrosis. $\mathrm{Br} \mathrm{J}$ Oral Maxillofac Surg 2017;55(3):230-4. 10.1016/j.bjoms.2016.12.006.

25. D Souza J, Lowe D, Rogers SN. Changing trends and the role of medical management on the outcome of patients treated for osteoradionecrosis of the mandible: experience from a regional head and neck unit. Br J Oral Maxillofac Surg 2014;52(4):356-62.

26. DelanianS, ChatelC,PorcherR, DepondtJ,LefaixJL.Complete restoration of refractory mandibular osteoradionecrosis by prolonged treatment with a pentoxifylline-tocopherolclodronate combination (PENTOCLO):a phase II trial. Int $J$ Radiat Oncol Biol Phys 2011;80:832-9.

27. Rodan GA, Fleisch HA. Biphosphonates: mechanisms of action. J Clin Invest 1996;97:2692-6.

28. Delanian S, Lefaix JL, Maisonobe T, Salachas F, Pradat PF. Significant clinical improvement in radiation-induced lumbosacral polyradiculopathy by a treatment combining pentoxifylline, tocopherol, and clodronate (Pentoclo). J Neurol Sci 2008;275:164-6.

29. Simões A, Eduardo FP, Luiz AC, Campos L, Sá PH, Cristófaro M, Marques MM, Eduardo CP. Laser phototherapy as topical prophylaxis agains head and neck cancer radiotherapyinduced oral mucositis: comparison between low and high/ low power lasers. Lasers Surg Med 2009;41(4):264-70.

30. Wilson M. Lethal photosensitization of oral bacteria and its potential application in the photodynamic therapy of oral infections. Photochem Photobiol Sci 2004;3(5):412-8.

31. Qiao J, Wang S, Wen Y, Jia H. Photodynamic effects on human periodontal-related cells in vitro. Photodiagnosis Photodyn Ther 2014;11(3):290-9. doi: 10.1016/j.pdpdt.2014.04.001.
32. Ribeiro GH, Minamisako MC, Rath IBS, Santos AMB, Simões A, Pereira KCR. Osteoradionecrosis of the jaws: case series treated with adjuvante low-level laser therapy and antimicrobial phodynamic therapy. J Appl Oral Sci 2018. doi: http://dx.doi.org/10.1590/1678-7757-2017-0172.

33. Srinivasan K, Chitra S. The Application of ozone in dentistry: a systematic review of literature. Sch J Dent Sci 2015;2(6):373-7.

34. Nogales CG, Ferrari PH, Kantorovich EO, Lage-Marques JL. Ozone therapy in medicine and dentistry. J Contemp Dent Pract 2008;9:75-84.

35. Batinjan G, Zore IF, Vuletić M, Rupić I. The use of ozente in the prevention of osteoradionecrosis of the jaw. Saudi Med J 2014;35(10):1260-3.

36. Agrillo AF, Filiaci V, Ramieri E. Riccardi D, Quarato C, Rinna $\mathrm{P}$, et al. Bisphosphonate-related osteonecrosis of the jaw (BRONJ): 5-year experience in the treatment of 131 cases with ozone therapy. Eur Rev Med Pharmacol Sci 2012;16:1741-7.

37. Agrillo AF, Ungari C, Filiaci F, Priore P, Iannetti G. Ozone therapy in the treatment of avascular bisphosphonate-related jaw osteonecrosis. J Craniofac Surg 2007;18(5):1071-5.

38. Dai T, Tian Z, Wang Z, Qiu W, Zhang Z, He Y. Surgical management of osteoradionecrosis of the jaws. JCraniofac Surg 2015;26(2):175-9. doi: 10.1097/SCS.0000000000001445.

39. Suh JD, Blackwell KE, Sercarz JA, Cohen M, Liu JH, Tang $\mathrm{CG}$, et al. Disease relapse after segmental resection and free flap reconstruction for mandibular osteoradionecrosis. Otolaryngol Head Neck Surg 2010;142(4):586-91. 